\title{
Grand challenges for medical physics in radiation oncology
}

Citation for published version (APA):

Fiorino, C., Jeraj, R., Clark, C. H., Garibaldi, C., Georg, D., Muren, L., van Elmpt, W., Bortfeld, T., \& Jornet, N. (2020). Grand challenges for medical physics in radiation oncology. Radiotherapy and Oncology, 153, 7-14. https://doi.org/10.1016/j.radonc.2020.10.001

Document status and date:

Published: 01/12/2020

DOI:

10.1016/j.radonc.2020.10.001

Document Version:

Publisher's PDF, also known as Version of record

Document license:

Taverne

Please check the document version of this publication:

- A submitted manuscript is the version of the article upon submission and before peer-review. There can be important differences between the submitted version and the official published version of record.

People interested in the research are advised to contact the author for the final version of the publication, or visit the DOI to the publisher's website.

- The final author version and the galley proof are versions of the publication after peer review.

- The final published version features the final layout of the paper including the volume, issue and page numbers.

Link to publication

\footnotetext{
General rights rights.

- You may freely distribute the URL identifying the publication in the public portal. please follow below link for the End User Agreement:

www.umlib.nl/taverne-license

Take down policy

If you believe that this document breaches copyright please contact us at:

repository@maastrichtuniversity.nl

providing details and we will investigate your claim.
}

Copyright and moral rights for the publications made accessible in the public portal are retained by the authors and/or other copyright owners and it is a condition of accessing publications that users recognise and abide by the legal requirements associated with these

- Users may download and print one copy of any publication from the public portal for the purpose of private study or research.

- You may not further distribute the material or use it for any profit-making activity or commercial gain

If the publication is distributed under the terms of Article $25 \mathrm{fa}$ of the Dutch Copyright Act, indicated by the "Taverne" license above, 
Review Article

\title{
Grand challenges for medical physics in radiation oncology
}

\author{
Claudio Fiorino ${ }^{\mathrm{a}, *}$, Robert Jeraj ${ }^{\mathrm{b}, \mathrm{c}}$, Catharine H. Clark ${ }^{\mathrm{d}}$, Cristina Garibaldi ${ }^{\mathrm{e}}$, Dietmar Georg ${ }^{\mathrm{f}}$, \\ Ludvig Muren ${ }^{\mathrm{g}}$, Wouter van Elmpt ${ }^{\mathrm{h}}$, Thomas Bortfeld ${ }^{\mathrm{i}}$, Nuria Jornet ${ }^{\mathrm{j}}$
}

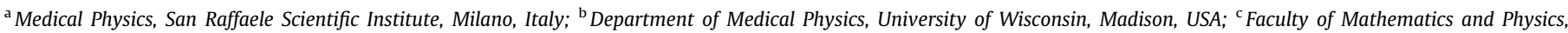

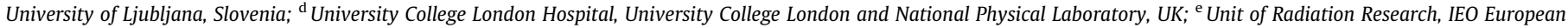

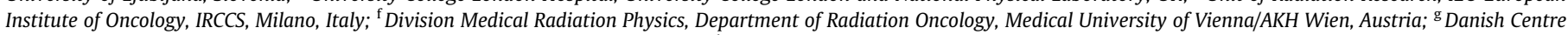

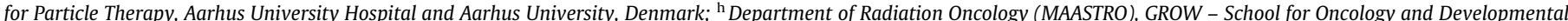

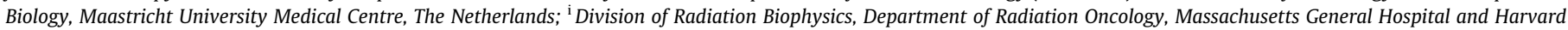
Medical School, Boston, USA; 'ं Servei de Radiofisica i Radioprotecció, Hospital Sant Pau, Barcelona, Spain
\end{abstract}

\section{A R T I C L E I N F O}

\section{Article history:}

Received 19 May 2020

Received in revised form 2 October 2020

Accepted 2 October 2020

Available online 8 October 2020

\section{Keywords:}

Medical physics

Radiation oncology

AI

Target definition

Radiobiology models

Leadership

\begin{abstract}
A B S T R A C T
Medical physics has made considerable contributions to recent advances in radiation oncology. Medical physicists are key players in the clinical and scientific radiation oncology context due to their unique skill sets, flexibility, clinical involvement and intrinsic translational character. The continuing development and widespread adoption of "high-tech" radiotherapy has led to an increased need for medical physics involvement. More recently, our field is rapidly changing towards an era of "precision oncology". These changes have opened new challenges for the definition of the professional and scientific roles and responsibilities of medical physicists. In this paper, we have identified four grand challenges of medical physics in radiation oncology: (1) improving target volume definition, (2) adoption of artificial intelligence and automation, (3) development of predictive models of biological effects for precision medicine, and (4) need for leadership. New visions and suggestions to orientate medical physics to successfully face these new challenges are summarized. We foresee that the scientific and professional challenges of our times are pushing medical physicists to accelerate toward multidisciplinarity. Medical physicists are expected to innovatively drive interactions and collaborations with other specialists outside radiation oncology while the radiation physics core will remain central. Medical physicists will retain strong and pivotal roles in quality, safety and in managing ever more complex technologies. The new challenges will require medical physicists to continuously update skills and innovate education, adapt curricula to include new fields, reinforce multi-disciplinary attitude and spirit of innovation. These challenges require visionary and open leadership, which is able to merge established roles with the exciting new fields where medical physics should increasingly contribute.
\end{abstract}

(c) 2020 Elsevier B.V. All rights reserved. Radiotherapy and Oncology 153 (2020) 7-14
Radiation medicine started with the discovery of X-rays and radioactivity at the end of the 19th century, leading to diagnostic and therapeutic applications of radiation. Several Nobel prizes in physics and chemistry are part of the history of medical physics in imaging and therapy, with Wilhelm Röntgen and Marie Curie considered by many as the "founders" of the applications of physics to medicine.

More recently, Nobel prizes also in medicine have been awarded to physicists for their achievements, such as the discoveries concerning the molecular structure of DNA, the development of computer assisted tomography (CT), or discoveries concerning magnetic resonance imaging (MRI). In radiation oncology,

* Corresponding author at: Medical Physics, San Raffaele Institute, Via Olgettina 60, 20132 Milano, Italy.

E-mail address: fiorino.claudio@hsr.it (C. Fiorino). physicists were involved from the pioneering applications at the end of the 19th Century, and by 1912-1913 the first physicists were appointed to hospital positions (in Munich and London) [1]. Also academic positions for medical physics appeared early, e.g. Sidney Russ as the first chair in physics appointed at the London medical school in 1920, or Rolf Sievert being appointed as a full professor of medical physics in 1941 in Stockholm.

Ever since, medical physicists ${ }^{1}$ have contributed to the technological and clinical advances of radiotherapy and constitute a key profession with a central role within the multidisciplinary approach of oncological care [2,3]. Today, medical physicists are responsible (with other professionals) for guaranteeing a safe and optimal use

\footnotetext{
${ }^{1}$ In the context of this contribution, a medical physicist is defined as a physicist employed in hospitals or medical research institutions, being in charge of medical applications of radiation, imaging, as well as radiation protection
} 
of technology in medicine; their flexibility, clinical involvement, intrinsic multi-disciplinary character and unique skills are well recognized and valued both scientifically and clinically, in particular in radiation oncology. Another pivotal point relates to the diverse "job profiles" in medical physics, covering clinical service, academia and research, clinical development and implementation as well as research and development in industry. This diversity is of great value to the medical field and to radiation oncology in particular.

The continuing development and widespread adoption of "high-tech" radiotherapy in recent decades have led to the increased involvement of medical physicists [2-4]. More recently, radiation oncology is changing following the current evolution towards the "precision oncology" era [5]. These developments opened a debate in the radiation oncology physics community regarding the redefinition of medical physics roles and responsibilities in these new scenarios $[2,6]$.

\section{The ESTRO Budapest vision meeting}

This paper was prepared by members of a task group on the "Future of Medical Physicists in Radiation Oncology", created by the ESTRO physics committee. In collaboration with the AAPM working group on Future of Medical Physics Research and Academic Training (FUTURE), it organized a think tank meeting on "the most provocative questions for medical physicists in Radiation Oncology" that was held in Budapest in October 2019. This workshop involved not only medical physicists but also other infield and out-of-field experts, acknowledged at the end of this paper.

A summary of the major organizational issues can be found in the Supplementary material, including the process to select the four "most provocative questions" that were here identified as the "grand challenges", with a 10-year horizon. Fig. 1a-d summarizes in word clouds the discussions referred to the four debated challenges.

Inspired by the lively discussions held in this workshop, the scope of this paper was to present visions and suggestions of the task group, aiming to identify priorities for the future grand challenges for medical physics in radiation oncology.

\section{Target definition transformed from an art to science}

Despite the availability of better and better imaging information and the continuously improving knowledge of tumor spread, clinical target volume (CTV) delineation continues to be affected by large inter- and intra-observer variability $[7,8]$. In other words, delineating the CTV can be still considered as an art, expertly performed by clinicians, according to its literal meaning, intended as a "skill acquired by experience, study, or observation" (https://www. merriam-webster.com/dictionary/art). There is therefore considerable room for reducing the uncertainties in CTV delineation through a scientifically-based approach driven by medical physicists. Some evidence suggests that patients are over-treated by the use of too wide CTV margins [9]. For instance, the inclusion of loco-regional lymph nodes in the CTV for elective nodal irradiation often comes with a many-fold volume increase [12], with a negative impact on the surrounding healthy tissues and unclear benefit for survival for some tumor sites such as breast and prostate $[13,14]$. A few studies looking into reducing CTV margins showed promising results but suffered from large statistical uncertainties $[10,11]$.

Despite the considerable recent advances in imaging, microscopic extensions of the GTV will remain invisible since even advanced imaging techniques are still unlikely to reach the spatial resolution required to detect a few or single cells. Similarly, lymphatic spread may remain invisible and uncertain. Moreover, the interplay of different treatment modalities, which is becoming the standard of care for some tumor sites, is not well understood. Systemic therapy can take care of microscopic disease and may reduce the need for CTV expansions [15]. The role of the CTV needs to be re-defined, for instance when synergistic effects between radiation and immunotherapy are being considered [16]. Physicists can help to address these substantial challenges from a number of angles:

1) It is of primary relevance to collect and combine data such as advanced functional imaging and other biomarker data to enable better characterization of tumor spread characteristics, including lymphatic spread and tumor/host interactions. It has been shown how macroscopic MR imaging can provide microscopic tissue characteristics [17-21]. It will be important to also include longitudinal data, i.e. changes over time. Physicists, among others, have to make sure that the data are FAIR (findable, accessible, interoperable, and reusable). When data are not available, physicists should be involved in collecting new data through clinical trials that are designed similar to physics experiments and can challenge clinical practice, for example by substantially reducing CTV margins.

2) Medical physicists, in collaboration with biologists and biophysicists, should explore models for tumor spread pathways [22] as well as the effect of combined treatments on microscopic disease spread, such as radiationimmunotherapy interplay [23].

3) Moving toward the development of a framework for probabilistic definition of the CTV is of paramount importance $[24,25]$. The standard binary (tumor/no tumor) definition does not capture the underlying probabilistic nature of the problem. A probabilistic approach to CTV definition requires the integration of data from imaging biomarkers (e.g., radiomics), patterns of recurrence, pathology data, data from clinical trial with shrinking volume and tumor likelihood map, in order to quantify the risk of marginal recurrence and balance competing risks.

4) Initial steps forward would be to implement the most recent CTV consensus guidelines and e.g. to expand the GTV automatically while respecting anatomic barriers to tumor spread [26]. The approaches should be developed for and could be tested in specific disease sites such as head-andneck, lung and central nervous system.

\section{Development and implementation of artificial intelligence in radiation oncology}

Artificial Intelligence (AI) based solutions are currently entering our field for a number of applications [27,28], expecting to impact at professional, health system and patient level, including better access to treatment $[29,30]$. These solutions need to follow the same technology adoption process as other engineering principles applied in medicine [31]. First, a clinical unmet need or a problem is identified and defined where novel solutions are suggested based on the proposed requirements; next, a validation phase follows to test if the new solutions meet the requirements for use in clinical practice; before finally facilitating end users (e.g. clinicians, radiation therapists, medical physicists) by understanding the principles of AI, crucial for successful and safe implementation in clinical practice [32]. The following four key points are seen as major priorities for medical physics in this area: 
a
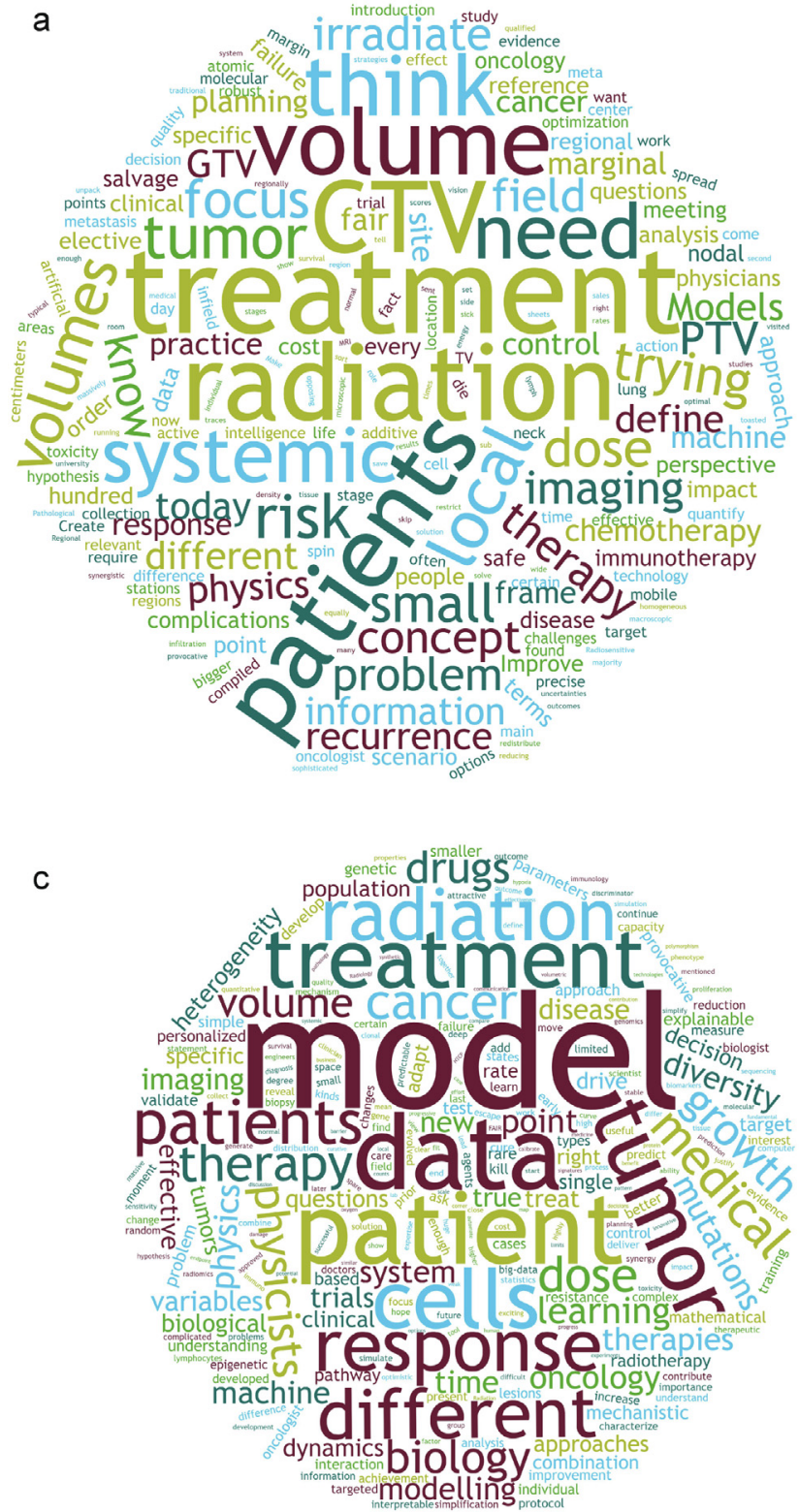

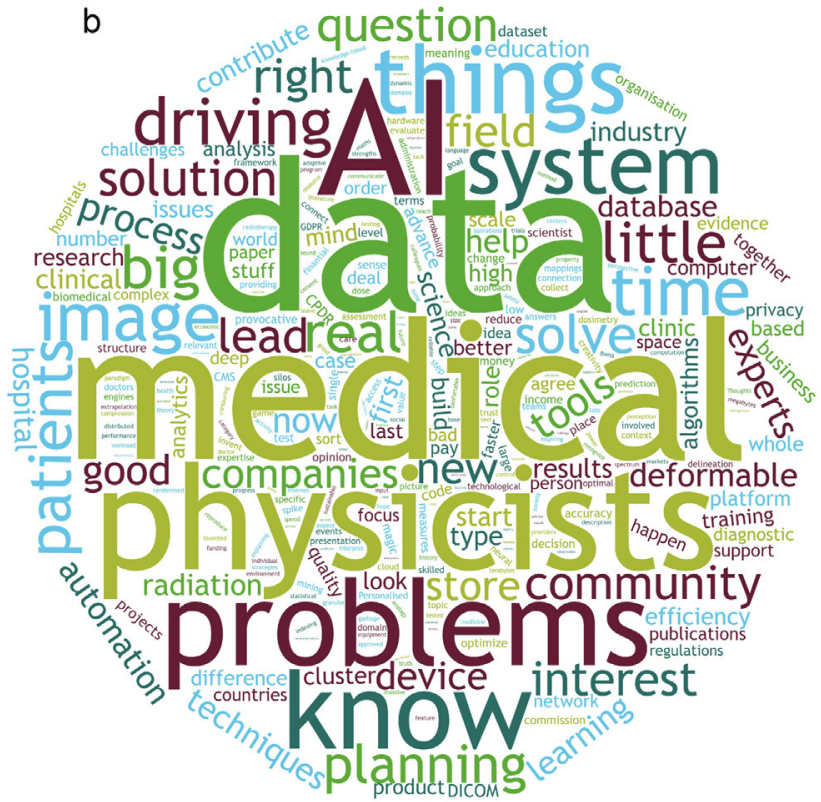

d

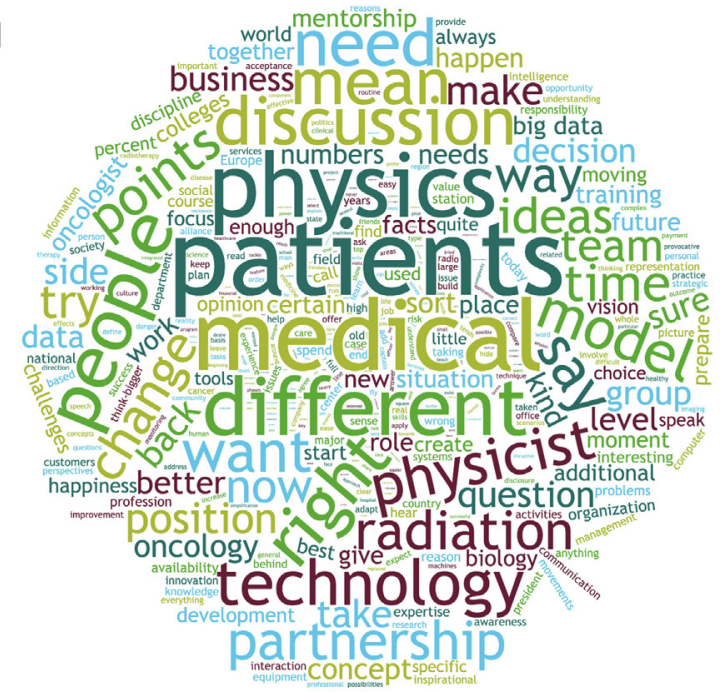

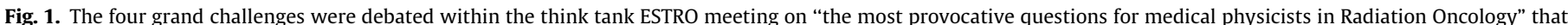

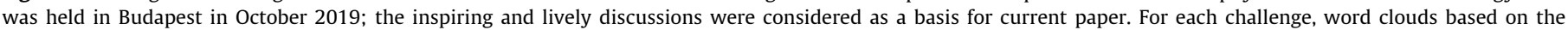

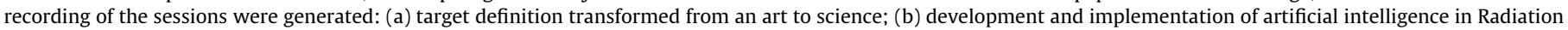
Oncology; (c) modeling biological effects in the era of personalized Radiation Oncology; (d) leadership in the changing world of Radiation Oncology.

1) Implementation and customization of AI technology. The long tradition of successful implementation of new technology mainly comes from the collaboration between medical physicists and physicians, nurses and technologists. This environment places medical physicists in a unique position to contribute to the implementation of $\mathrm{AI}$ in the clinical environment together with the AI specialists [27,33]. Therefore, medical physicists should now widen their collaborative space and work together with data scientists and engineering specialists to introduce AI safely and efficiently into the current care path of patients. This starts with an understanding of the technology presently at hand. Although many medical physicists have, by training, strong analytical skills for problem solving [34-37], detailed knowledge about current machine learning, deep learning or other AI techniques is not ubiquitous [32].
2) Development of AI technology. Playing the central active role in the upcoming AI field is attractive for physicists who contribute to the definition of the directions that should be taken to secure proper clinical implementation. Collaboration with industry and scientific computing research groups is therefore of utmost importance to have access to the latest technology and scientific insights. A simplistic approach could be to team up with data science/data engineers to implement already available tools. However, application and interpretation need to come from the medical physics field itself. The success of AI approaches does not only depend on the quality and amount of data needed for training but also on the ability to rephrase the clinical questions towards the data science engineers. Again, collaboration with other disciplines is a key factor for success. 
3) Facilitating access to proper data. AI typically needs to deal with having access to data [38-40]. The hospital IT environment landscape is changing rapidly and medical physicists should play an active role in this to guarantee access to data sources for AI development. Besides advice on the requirements for the IT frameworks, medical physicists together with the physicians are responsible for interpreting and developing the appropriate models: e.g. prediction models [41,42] or more advanced solutions [43-45]. Technology for data mining is only a single aspect of this work, as challenges are also present in aligning the different stakeholders (IT, physician, legal/patient privacy etc), to strive for collaboration and keeping the common (clinical) goal. Also besides quantity, the quality (e.g. richness, size and amount of curation) of the datasets is of utmost importance for successful training and implementation of $\mathrm{AI}$ models in clinical practice.

4) Education and training for AI skills. Besides implementation, discussion and interaction is also needed with industry to roll out these new technologies with the innovators and early adopters; however, these partners are currently only a limited fraction of medical physicists, typically located in the larger academic hospitals. Medical physicists dedicated to clinical activities need training for these new developments and programs for commissioning and quality assurance need to be developed. Basic knowledge of AI in the curricula for medical physicists must be secured [46]. The extent of training needed will depend on the specific implementations but as AI applications will be classified as medical devices, the medical physicists should also approach these techniques as such with proper testing and validation (QA) programs in place [47]. Hence, understanding AI models is a crucial step towards clinical implementation, otherwise the outcome of AI based models will be accepted without careful assessment of possible flaws or scenarios that are not predicted properly. In addition, medical physicists, once properly trained, are expected to have an essential role to play in ensuring that other members of the team could become more aware of the pros and cons of $\mathrm{AI}$ models and tools.

\section{Modeling biological effects in the era of personalized radiation oncology}

Medical physics has a long tradition of contributing to modeling biological effects in radiation oncology. High-impact examples are the quantification of dose-volume effects based on clinical data, being relevant in everyday radiotherapy planning and optimization $[48,49]$ as well as the adaptation and use of fractionation models aimed to translate physical doses into biologically equivalent doses for tumors [50]. Actions aiming to maximize the contribution of medical physics to this field are summarized in the following key points:

1) Medical physicists have fundamental physics skills to set up mathematical descriptions of biological or clinical problems, combined with ability to simplify complex relationships to the greatest extent. In addition, medical physics training of fundamental mathematical, statistical, biological and clinical aspects allow medical physicists to relatively easy interact with the professionals required for successful interdisciplinary teams to tackle modeling problems. This makes them uniquely positioned to develop models that describe either population trends or individual behavior of cancer and associated therapies. Medical physicists should focus on developing manageable few-parameter models that robustly capture principal components of the picture and combine heterogeneous information (e.g. dose/volume, clinical, biological, genomic, quantitative imaging. ..) into interpretable and generalizable predictive models [41,51]. Machine learning and AI-based models, derived from data can be useful, but an appropriate level of understanding and extensive validation are needed to give sufficient confidence for clinical use [52].

2) Medical physicists have made significant contributions in radiation biology. However, modern radiotherapy is often delivered in combination with chemotherapy, targeted therapy or immunotherapy. Therefore, it is important to acquire sufficient knowledge and to connect with appropriate expertise (e.g. medical oncologists, imaging experts, pathologists, biologists and immunologists) to be able to contribute in modeling new challenging issues related to the new paradigms of radiation oncology in curing and/or preventing metastatic spread [53]. This includes the interaction with the immune system [54], tumor evolution and metastases [55,56], tumor regression [57], lymphocyte irradiation [58] and toxic effects of combined/personalized treatments $[59,60]$. In order to be able to address these new classes of problems, teaching curricula will need to be revised to include contemporary materials reflecting current state and evolution of radiation oncology.

3) Medical physicists should be directly involved in design, execution and interpretation of clinical trials and in preclinical experiments. Clinical trials/pre-clinical experiments should target testable hypotheses originating from the models themselves. These can then either prove or disprove the model or provide grounds for additional insights that would enable refinements of the available models [61]. As previously underlined in the context of CTV definition and AI implementation, medical physicists should also act as facilitators of data gathering and data farming, contributing to building and managing advanced data sharing platforms, as well as within new approaches such as umbrella protocols and basket trials [62-64]. Modern teaching curricula should include more materials on clinical trial design and more emphasis should be put on adding training sessions in clinical trial design specifically aimed at medical physicists at national and international meetings.

4) In order to maximize the contribution of medical physicists, their education needs to substantially corroborate biology and radiobiological skills to a larger extent than currently captured in our curricula $[2,4,6,46]$. In addition, medical physicists should acquire a sufficient level of data analytics expertise (e.g., biostatistics, big data, AI) that can constructively contribute to clinical trial design, execution and analyses.

Overall, medical physicists are expected to contribute in a relevant way to the new challenges of personalized radiation oncology in the current, rapidly changing times. To successfully build on the long tradition of modeling normal tissue and tumor response, both proactive and reactive actions must address the new issues. These require fast adaptation towards the multi- and trans-disciplinary nature of radiation oncology. This process is likely to push more and more medical physicists out of their traditional domains, encountering biology-oriented disciplines and clinical, biology and technical experts outside the strict radiotherapy domain. At the same time, the strong roots of medical physicists in the clinical environment remain a remarkable and unique resource in supporting the translation between biological, pre-clinical and clinical applications. In order to respond in the best way to these exciting challenges, medical physicists are required to orientate their 
efforts in adapting and increasing their skills and to actively promote new roles and responsibilities.

\section{Leadership in the changing world of radiation oncology}

Medical physicists not only guard quality and safety in radiation oncology, but also often take the first, disruptive steps towards change and improvement. Historically, medical physicists have contributed to the major technological developments in radiation oncology. However, technology only serves a purpose if it addresses a clinical need. Technological development "ad infinitum" is not needed, and time and resources should not be wasted [65]. A challenging example concerns the highly unequal distribution of technology within Europe and even within countries/regions (for instance between large academic Institutions and small hospitals); and still more, this is evident in middle and low income countries. The roles of national and international networks aimed to better ensure proper and safe implementation of new technology as well as of national and international societies (such as IAEA, ESTRO, ASTRO, EFOMP, AAPM. ..) in supporting auditing, education and tutoring are of primary importance in this context. The future of radiation oncology will unavoidably require a more equalitarian access to treatment, and this also needs adequate leadership in medical physics, including challenging actions toward middle and low income countries. The future will also be in further personalization of the treatment $[5,31,51,52,65,66]$. This will be achieved through individualized biological based decisions underpinned by robust models. These models will be developed through deep learning and data mining for which the standardization and creative development would benefit of the contribution of medical physicists [67]. Within this scenario, some major key points may be underlined:

1) Medical physicists should develop a mutually synergistic partnership with the other professionals in radiation oncology in leading our field together. Here we can consider the analogy of the airplane. The pilots and crew in the plane work together and from time to time one or other is in charge of different aspects of the 'flight'. This ensures both the fleet and the passengers arrive safely and effectively at the common destination, by the most appropriate means for the scenario. The professions in radiation oncology have different training, which give them different skills. Radiation Oncology needs all of these different types of skills to effectively move the field forward safely and therefore the leadership needed to achieve this must be multi-faceted. The key lies in choosing the right areas for each to lead in, and hence the changing world of radiation oncology will also need medical physicists to be leaders.

2) The advancement of any field needs episteme (know what, concepts and logic), techne (know-how, inter-disciplinary) and phronesis (know what, when and for whom, researchers, practitioners etc). To achieve this in radiation oncology we need both an artistic and scientific approach. Medicine for the individual requires the art to be underpinned by the strongest science, which is where physics plays a crucial role, in identifying and developing new scientific concepts that can support radiation oncology developments.

3) To continue to be leaders, the responsibility lies with the medical physicists themselves. The majority of clinical medical physicists work in hospitals, delivering radiation oncology to the best of their ability and in some cases leaving little time for innovative thinking [6]. This may cause frustration in medical physics teams, therefore it is crucial to have the right leaders in the right position with the right education and training and networks to drive innovation. Not secondarily, educating outsiders (policy makers, mangers) and the public regarding the essential role of medical physicists is also relevant $[46,68]$.

4) The fact that radiation oncology has worked so well in the past is because medical physicists were part of the team. The role for Medical physicists should be to horizon scan to identify relevant scientific and technological advancements that may have relevance to radiation oncology such as the role of wearable devices or flexible printable detectors, as only two examples. This then naturally leads to leadership of all technological innovations (in both soft and hard technologies) that will be introduced in the hospital, where the medical physicists will play a central role guiding the clinical engineers, data scientists and biomedical engineers in asking the right questions. Medical physicists will continue to lead in facilitation of implementation of technology, including new directions such as AI, as discussed in a previous section, and ensuring explainability and impact for patients [65.]. This has a wider reach in the hospital beyond radiation oncology, radiology and nuclear medicine departments. Therefore, for optimal effective leadership, medical physics departments should have some autonomy to not only be focused on radiation oncology, such that they are able employ a greater variety of scientists, as has been seen in imaging departments. In this way, both radiation oncology and other medical disciplines would benefit from the inter-disciplinarity across the whole field of medical physics.

\section{Visions for grand challenges: concluding remarks}

Table 1 summarizes key bullet points (with a 10-year horizon) for the four major grand challenges. Importantly, although identified under the angle of medical physics, they may be, at least in part, of interest to the whole radiation oncology community. New visionary roads are needed to optimally address the grand challenges of our times and of the coming future. A common message, largely present in all four challenges, is that the field of medical physics should accelerate toward multidisciplinarity [3,4,69-71], with different problems and unexplored fields to be explored. This is connected with the intrinsic translational nature of medical physics but also contains something new, mostly linked to the rapid evolution toward personalized medicine, stressing the growing need of hybridization. Medical physics in radiation oncology has to extend its interest beyond the core of radiation physics such as high-tech expertise, quality assurance and radiation safety. Medical physicists are expected to courageously move away from the "radiation oncology exclusivity", increasing and activating interactions and collaborations with other specialists such as engineers, statisticians, biologists, mathematicians, biophysicists, data scientists, imaging scientists as well as physicians outside radiation oncology including radiologists, medical oncologists, immunologists, pathologists and surgeons. This evolution can be considered perfectly in line with the attitude of medical physicists to work as part of a team and with the intrinsic multi-disciplinary nature of radiation oncology; in other words, with the traditional ability of medical physics to adapt its roles to new and disruptive challenges to the progress of radiation oncology.

A relevant issue concerns the limited availability of resources to make these processes faster, through an adequate support in terms of dedicated time and man-power. The complexity of this point is out of the aims of current work; however, we may expect that extending the interests toward the "new fields" could facilitate the access to grants and funds that can better attract talented young physicists as well as create more opportunities for dedicated 
Table 1

\begin{tabular}{|c|c|c|}
\hline Challenges & Key words & Bullet points \\
\hline $\begin{array}{l}\text { Target definition } \\
\text { transformed from an } \\
\text { art to science }\end{array}$ & $\begin{array}{l}\text { image-based tumor characterization, data collection, } \\
\text { clinical trials, tumor spread, probabilistic targets, } \\
\text { guidelines implementation }\end{array}$ & $\begin{array}{l}\text { 1) MPs should collect and combine biological and imaging data, enabling bet- } \\
\text { ter characterization of tumor spread characteristics. } \\
\text { 2) MPs should model the effect of combined treatments on tumor spread } \\
\text { pathway. } \\
\text { 3) MPs should develop a framework for probabilistic definition of CTV to } \\
\text { quantify the risk of marginal recurrence and balance competing risks. } \\
\text { 4) Existing clinical guidelines should be implemented as algorithms in treat- } \\
\text { ment planning systems }\end{array}$ \\
\hline $\begin{array}{l}\text { Development and } \\
\quad \text { implementation of } A I \\
\quad \text { in } R O\end{array}$ & $\begin{array}{l}\text { AI implementation, customizing AI solutions, data access, } \\
\text { translating clinical requests, AI-oriented education and } \\
\text { training }\end{array}$ & $\begin{array}{l}\text { 1) MPs are in a unique position to drive implementation and customization } \\
\text { of AI technology in RO, in collaboration with vendors of AI solutions. } \\
\text { 2) MPs are expected to contribute in specific AI developments, mostly in } \\
\text { teams including other specialists, such as engineers and data scientists. } \\
\text { 3) MPs will have a pivotal role in facilitating the access to the proper data, } \\
\text { needed for efficient and successful AI solutions and in striving collabora- } \\
\text { tion between different professions and sciences. } \\
\text { 4) Most clinical MPs will not be involved in developing AI solutions but will } \\
\text { consider them as additional medical devices; then, specific AI-oriented } \\
\text { education and training have to be set in the core curricula }\end{array}$ \\
\hline $\begin{array}{l}\text { Modeling biological } \\
\text { effects in the era of } \\
\text { personalized } R O\end{array}$ & $\begin{array}{l}\text { interpretable models, combined treatments, immunology } \\
\text { and immunotherapy, clinical trials, curriculum in biology }\end{array}$ & $\begin{array}{l}\text { 1) MPs have unique skills to set up simplistic, yet realistic biological models. } \\
\text { 2) Models should expand beyond RO to capture modern multi-modal } \\
\text { treatments. } \\
\text { 3) MPs should be involved in clinical trials and experimental designs to cap- } \\
\text { ture relevant modeling parameters. } \\
\text { 4) MPs should reach out of the traditional RO domain with updated curricula. }\end{array}$ \\
\hline $\begin{array}{l}\text { Leadership in the } \\
\quad \text { changing world of RO }\end{array}$ & $\begin{array}{l}\text { synergy, high scientific profile, multi-disciplinarity, } \\
\text { innovation, education, leadership selection }\end{array}$ & $\begin{array}{l}\text { 1) Synergy is needed between other RO professionals and MPs to lead the } \\
\text { field together: the leadership needed to achieve the best for the field must } \\
\text { be composed from all } \\
\text { 2) RO for the individual has both an "artistic" and scientific approach where } \\
\text { "art" must be underpinned by the strongest science } \\
\text { 3) The responsibility for leadership lies with the MPs themselves to have the } \\
\text { right leaders and the right education to drive innovation. } \\
\text { 4) The future of MP lies in MPs leading a multidisciplinary team of other } \\
\text { engineers and scientists. }\end{array}$ \\
\hline
\end{tabular}

MP: medical physics, MPs: medical physicists; RO: radiation oncology; ROs: radiation oncologists; AI: artificial intelligence.

resources to innovation and research for medical physics departments. Also due to this context, structured medical physics departments incorporating both clinical and scientific/research roles will also be pivotal in successfully facing these challenges $[2,4,6]$. If possible, the integration of different non-medical professionals within large and structured medical physics departments may represent a relevant additional value for radiation oncology.

This changing scenario will pose challenges concerning the preparation and selection of a new generation of visionary leaders. The radiation physics core will remain an important part of both clinical and scientific work in medical physics in radiation oncology, including the strong and pivotal role in managing quality, safety and ever more complex technology. In Europe there is a legal framework (EC directive) with varying national interpretations, which describes the role of the medical physics expert (MPE) and this cannot be ignored [72]. On the contrary, this has to be considered as a well assessed and strong base for medical physicists, primarily contributing to its strength in the clinical environment, with pivotal roles in assuring quality and safety, and even to its unique position in facing the new challenges. It is likely that the new challenges will rapidly translate into new roles and responsibilities that should gradually integrate and extend the current legal framework for the MPE in radiation oncology. New requests mean new (multi-disciplinary) fields to be explored, and this means the need for continuously updating skills and education, adapting our core curricula [46]. This point is likely to be one of the most challenging, due to the heterogeneous situations in the different European countries and to the intrinsically slow reactivity of the education systems. The multi-disciplinary nature of ESTRO and its flexibility can greatly contribute to accelerating and supporting these processes [6]. A shared leadership between the different disciplines within ESTRO, with particular emphasis on medical physics, would be beneficial. For better engagement with other fields of medical physics and the ability to integrate the best of them into radiation oncology, actions to reinforce and intensify relationships with other international medical physics societies are of high relevance and importance.

Finally, the need for action to facilitate efficient and equal distribution of technology in middle and low-income countries is an urgent and highly challenging issue of our times. Given the expected increase in cancer in these countries in the coming years [73-75], the pivotal role of medical physicists is crucial and new generations of leaders must be able to merge innovation, efficiency and sharing to create optimal health for all, together [76].

\section{Conflicts of interest}

No conflicts of interest to declare.

\section{Acknowledgments}

The authors gratefully acknowledge all the other participants to the Budapest ESTRO think-tank meeting (October 24th 2019) on "the most provocative questions to medical physics in radiation oncology": M. Alber, Heidelberg University Hospital, Heidelberg, Germany - A. Cortese, CEO ESTRO, Brussels, Belgium, A. Dekker, Maastricht University Medical Centre, Maastricht, The Netherlands - H. Enderling, H. Lee Moffitt Cancer Center and Research Institute, Tampa, USA - M. Guckenberger, University Hospital Zürich, Switzerland - M. Gooding, Mirada Medical Ltd, Oxford Centre for Innovation, UK - B. Heijmen, Erasmus MC, Rotterdam, The Nether- 
lands - Y. Jongen, IBA, Louvain-la-Neuve, Belgium - M. Kamphuis, Academic Medical Center, University of Amsterdam, The Netherlands - R. Kikinis, Harvard Medical School, Boston, USA - T. Knöös, Skåne University Hospital, Lund University, Sweden - P. Lambin, Maastricht University Medical Centre, Maastricht, The Netherlands - Y. Lievens, Ghent University Hospital and Ghent University, Ghent, Belgium - B. McClean, St Luke's Radiation Oncology Centre, Rathgar, Dublin, Ireland - B. Nailon, NHS Lothian \& The University of Edinburgh, Edinburgh, UK - H. Nyström, Skandion Clinic, Uppsala, Sweden - U. Oelfke, The Institute of Cancer Research and the Royal Marsden NHS Foundation Trust, London, UK - W. Oyen, Humanitas University and Clinical and Research Center, Milan, Italy; Rijnstate Hospital, Dept. of Radiology and Nuclear Medicine, Arnhem, The Netherlands; Radboud UMC, Dept. of Radiology and Nuclear Medicine, Nijmegen, The Netherlands M. Schwarz, Trento Hospital and TIFPA-INFN, Trento, Italy - FA. Siebert, University Hospital of Schleswig-Holstein, Campus Kiel, Germany - A. Simitsis, Athena Research and Innovation Center, Athens, Greece - B. Slotman, Amsterdam University Medical Centers, Amsterdam, The Netherlands - U. van der Heide, The Netherlands Cancer Institute, Amsterdam, Netherlands - V. Valentini, Fondazione Policlinico Universitario A. Gemelli IRCCS, Rome, Italy - D. Verellen, Iridium Kankernetwerk, Antwerp University, Antwerp, Belgium - B. Wouters, University of Toronto, Toronto, Canada - D. Zips, University Hospital Tübingen, Tübingen, Germany. A. Laussucq and A. Barroso (ESTRO Office) are gratefully acknowledged for their great organization and logistic support. All the people contributing in sending suggestions for the selection of the "most provocative questions" (in total, 104 contributions) are gratefully acknowledged.

\section{Appendix A. Supplementary data}

Supplementary data to this article can be found online at https://doi.org/10.1016/j.radonc.2020.10.001.

\section{References}

[1] Keevill S. Physics and medicine: an historical perspective. Lancet 2011;379:1517-24.

[2] Bortfeld T, Jeraj R. The physical basis and future of radiation therapy. Br J Radiol 2011;84:485-98.

[3] Fiorino C, Guckenberger M, Schwarz M, Heide UA, Heijmen B. Technologydriven research for radiotherapy innovation. Mol Oncol 2020. in press.

[4] Bortfeld T, Torresin A, Fiorino C, Andreo P, Gagliardi G, Jeraj R, et al. The research versus clinical service role of medical physics. Radiother Oncol 2015;114:285-8.

[5] Baumann M, Krause M, Overgaard J, Debus J, Bentzen SM, Daartz J, et al. Radiation oncology in the era of precision medicine. Nat Rev Cancer 2016;16:234-49.

[6] Fiorino C, Muren LP, Clark CH, van Elmpt W, Jornet N. Expanding the scientific role of medical physics in radiotherapy: time to act. Radiother Oncol 2015;117:401-2.

[7] Steenbakkers RJ, Duppen JC, Fitton I, Deurloo KE, Zijp L, Uitterhoeve AL, et al. Observer variation in target volume delineation of lung cancer related to radiation oncologist-computer interaction: a 'Big Brother' evaluation. Radiother Oncol 2005:77:182-90.

[8] Hong TS, Tomé WA, Harari PM. Heterogeneity in head and neck IMRT target design and clinical practice. Radiother Oncol 2012;103:92-8.

[9] Apolle R, Rehm M, Bortfeld T, Baumann M, Troost EGC. The clinical target volume in lung, head-and-neck, and esophageal cancer: lessons from pathological measurement and recurrence analysis. Clin Transl Radiat Oncol 2017;3:1-8.

[10] Nestle U, Schimek-Jasch T, Kremp S, Schaefer-Schuler A, Mix M, Kưsters A, et al. Imaging-based target volume reduction in chemoradiotherapy for locally advanced non- small cell lung cancer (PET-Plan): a prospective randomised international multicentre trial. Lancet Oncol, 2020, in print.

[11] Contreras JA, Spencer C, DeWees T, Haughey B, Henke LE, Chin RI, et al. Eliminating postoperative radiation to the pathologically node-negative neck: long-term results of a prospective phase II study. J Clin Oncol 2019;37:2548-55.

[12] Biau J, Moreau J, Blanchard P, Thariat J, Miroir J, Lapeyre M. Reirradiation for head and neck squamous cell carcinoma: Indications and results. Cancer Radiother 2019;23:559-64.
[13] Poortmans PM, Collette S, Kirkove C, Van Limbergen E, Budach V, Struikmans $\mathrm{H}$, et al. Internal mammary and medial supraclavicular irradiation in breast cancer. N Engl J Med 2015;373:317-27.

[14] Roach M, Moughan J, Lawton CAF, Dicker AP, Zeitzer KL, Gore EM, et al. Sequence of hormonal therapy and radiotherapy field size in unfavourable, localised prostate cancer (NRG/RTOG 9413): long-term results of a randomised, phase 3 trial. Lancet Oncol 2018;19:1504-15.

[15] Punglia RS, Morrow M, Winer EP, Harris JR. Local therapy and survival in breast cancer. N Engl J Med 2007;356:2399-405.

[16] Van Limbergen EJ, De Ruysscher DK, Olivo Pimentel V, Marcus D, Berbee M, Hoeben A, et al. Combining radiotherapy with immunotherapy: the past, the present and the future. Br J Radiol 2017:90:20170157.

[17] Szczepankiewicz F, Lasič S, van Westen D, Sundgren PC, Englund E, Westin CF, et al. Quantification of microscopic diffusion anisotropy disentangles effects of orientation dispersion from microstructure: applications in healthy volunteers and in brain tumors. NeuroImage 2015;104:241-52.

[18] Mardor Y, Pfeffer R, Spiegelmann R, Roth Y, Maier SE, Nissim O, et al. Early detection of response to radiation therapy in patients with brain malignancies using conventional and high b-value diffusion-weighted magnetic resonance imaging. J Clin Oncol 2003;21:1094-100.

[19] Jeraj R, Bradshaw T, Simoncic U. Molecular imaging to plan radiotherapy and evaluate its efficacy. J Nucl Med 2015;56:1752-65.

[20] Gurney-Champion OJ, Mahmood F, Schie MI, Julian R, George B, Philippens MEP, et al. Radiother Oncol 2020;146:66-75.

[21] Pham TT, Liney GP, Wong K, Barton MB. Functional MRI for quantitative treatment response prediction in locally advanced rectal cancer. Br J Radiol 2017;90:20151078.

[22] Pouymayou B, Koechli C, Balermpas P, Guckenberger M, Unkelbach J. Analysis of lymphatic metastasis and progression patterns for clinical target volume (CTV) definition in head and neck squamous cell carcinoma (HNSCC). Acta Oncol 2019;58:1519-22.

[23] Grassberger C, Ellsworth SG, Wilks MQ, Keane FK, Loeffler JS. Assessing the interactions between radiotherapy and antitumour immunity. Nat Rev Clin Oncol 2019;16:729-45.

[24] Alber M, Thorwarth D. Multi-modality functional image guided dose escalation in the presence of uncertainties. Radiother Oncol 2014:111:354-9.

[25] Shusharina N, Craft D, Chen YL, Shih H, Bortfeld T. The clinical target distribution: a probabilistic alternative to the clinical target volume. Phys Med Biol 2018;63:155001.

[26] Shusharina N, Söderberg J, Edmunds D, Löfman F, Shih H, Bortfeld T. Automated delineation of the clinical target volume using anatomically constrained 3D expansion of the gross tumor volume. Radiother Oncol 2020;146:37-43.

[27] Thompson RF, Valdes G, Fuller CD, Carpenter CM, Morin O, Aneja S, et al. Artificial intelligence in radiation oncology: A specialty-wide disruptive transformation?. Radiother Oncol 2018;129:421-6.

[28] He J, Baxter SL, Xu J, Xu J, Zhou X, Zhang K. The practical implementation of artificial intelligence technologies in medicine. Nat Med 2019;25:30-6.

[29] Topol EJ. High-performance medicine: the convergence of uman and artificial intelligence. Nat Med 2019;25:44-56.

[30] Topol EJ. The Topol Review: Preparing the healthcare workforce to deliver the digital future 2019. https://topol.hee.nhs.uk/.

[31] Chetty IJ, Martel MK, Jaffray DA, Benedict SH, Hahn SM, Berbeco, et al. Technology for innovation in radiation oncology. Int J Radiat Oncol Biol Phys 2015;93:485-92.

[32] Xing L, Krupinski EA, Cai J. Artificial intelligence will soon change the landscape of medical physics research and practice. Med Phys 2018;45:1791-3.

[33] Tang X, Wang B, Rong Y. Artificial intelligence will reduce the need of clinical physicists. JACMP 2018;19:6-9.

[34] Malicki J. Medical physics in radiotherapy: The importance of preserving clinical responsibilities and expanding the profession's role in research, education, and quality control. Rep Pract Oncol Radiother 2015;20:161-9.

[35] American Association of Physicists in Medicine. Medical physicist: what do medical physicists do? https://www.aapm.org/medical_physicist/. Last accessed December 28, 2017.

[36] Australian College of Physical Scientists \& Engineers in Medicine. ASPSEM position on the roles and responsibilities of the qualified medical physicist. https://www.acpsem.org.au/documents/item/18. Last accessed December 28, 2017.

[37] Eudaldo T, Huizenga H, Lamm I-L, McKenzie A, Milano F, Schlegel W, et al. Guidelines for education and training of medical physicists in radiotherapy. Radiother Oncol 2004;70:125-35.

[38] Press G. Cleaning big data: most time-consuming, least enjoyable data science task, survey says. Forbes. https://www.forbes.com/sites/gilpress/2016/03/ 23/data-preparation-most-time-consuming-least-enjoyable-data-sciencetask-survey-says/amp/ (2016). Accessed Jan 18, 2019.

[39] Stupple A, Singerman D, Celi LA. The reproducibility crisis in the age of digital medicine. NPJ Digit Med 2019;2. https://www.nature.com/articles/s41746019-0079-z Accessed Feb 18, 2019.

[40] Miller DD. The medical AI insurgency: what physicians must know about data to practice with intelligent machines. NPJ Digit Med 2019;2:62.

[41] Lambin P, van Stiphout RG, Starmans MH, Rios-Velazquez E, Nalbantov G, Aerts HJ, et al. Predicting outcomes in radiation oncology-multifactorial decision support systems. Nat Rev Clin Oncol 2013;10:27-40. 
[42] El Naqa I, Kerns SL, Coates J, Luo Y, Speers C, West CML, et al. Radiogenomics and radiotherapy response modeling. Phys Med Biol 2017;62:R179-206.

[43] Hosny A, Parmar C, Coroller TP, Grossmann P, Zeleznik R, Kumar A, et al. Deep learning for lung cancer prognostication: A retrospective multi-cohort radiomics study. PLoS Med 2018;15:e1002711.

[44] El Naqa I, Bradley JD, Lindsay PE, Hope AJ, Deasy JO. Predicting radiotherapy outcomes using statistical learning techniques. Phys Med Biol 2009;54: S9-S30.

[45] Mak RH, Endres MG, Paik JH, Sergeev RA, Aerts H, Williams CL, et al. Use of crowd innovation to develop an artificial intelligence-based solution for radiation therapy targeting. JAMA Oncol 2019;5:654-61.

[46] Clark CH, Gagliardi G, Heijmen B, Malicki J, Thorwarth D, Verellen D, et al. Adapting training for medical physicists to match future trends in radiation oncology. Phys Imag Radiat Oncol 2019;11:71-5.

[47] El Naqa I, Ruan D, Valdes G, Dekker A, McNutt T, Ge Y, et al. Machine learning and modeling: data, validation, communication challenges. Med Phys 2018;45:e834-40.

[48] Kutcher GJ, Burman C. Calculation of complication probability factors for nonuniform normal tissue irradiation: The effective volume method. Int J Radiat Oncol Biol Phys 1989;16:1623-30.

[49] Marks LB, Yorke ED, Jackson A, Ten Haken RK, Constine LS, Eisbruch A, et al. Use of normal tissue complication probability models in the clinic. Int J Radiat Oncol Biol Phys 2010;76:S10-9.

[50] McMahon SJ. The linear quadratic model: usage, interpretation and challenges. Phys Med Biol 2018;64:01TR01.

[51] Van Der Schaaf A, Langendijk JA, Fiorino C, Rancati T. Embracing phenomenological approaches to normal tissue complication probability modelling: a question of method. Int J Radiat Oncol Biol Phys 2015;91:468-71.

[52] El Naqa I, Pandey G, Aerts H, Chien J-T, Andreassen CN, Niemierko A, et al. Radiation therapy outcomes models in the era of radiomics and radiogenomics: uncertainties and validation. Int J Radiat Oncol Biol Phys 2018;102:1070-3.

[53] Chamber AF. Tumor metastasis, physical sciences and the value of multidisciplinary collaborations. In: Mierke CT, editor. Physics of cancer. Bristol (UK): IOP Publishing; 2015.

[54] Valentinuzzi D, Simoncic U, Ursic K, Vrankar M, Turk M, Jeraj R. Predicting tumour response to anti-PD-1 immunotherapy with computational modelling. Phys Med Biol, 2019;64:025017.

[55] Jeong J, Oh JH, Sonke J-J, Belderbos J, Bradley JD, Fontanella AN, et al. Modeling the cellular response of lung cancer to radiation therapy for a broad range of fractionation schedules. Clin Cancer Res 2017;23:5469-79.

[56] Tannenbaum A, Georgiou TT, Deasy JO, Norton L. Control and the analysis of cancer growth models. Oper Theor: Adv Appl 2019;272:343-53.

[57] Fiorino C, Gumina C, Passoni P, Palmisano A, Broggi S, Cattaneo GM, et al. A TCP-based early regression index predicts the pathological response in neoadjuvant radio-chemotherapy of rectal cancer. Radiother Oncol 2018;128:564-8.

[58] Yovino S, Kleinberg L, Grossman SA, Narayanan M, Ford E. The etiology of treatment-related lymphopenia in patients with malignant gliomas: modeling radiation dose to circulating lymphocytes explains clinical observations and suggests methods of modifying the impact of radiation on immune cells. Cancer Invest 2013;31:140-4.

[59] Deist TM, Dankers FJWM, Valdes G, Wijsman R, Hsu IC, Oberije C, et al. Machine learning algorithms for outcome prediction in (chemo)radiotherapy: An empirical comparison of classifiers. Med Phys 2018;45:3449-59.

[60] Pouryahya M, Oh JH, Mathews JC, Deasy JO, Tannenbaum AR. Characterizing cancer drug response and biological correlates: a geometric network approach. Sci Rep 2018;8:6402.

[61] Tseng HH, Luo Y, Ten Haken RK, El Naqa I. the role of machine learning in knowledge-based response-adapted radiotherapy. Front Oncol 2018;8:266.

[62] Park JJH, Siden E, Zoratti MJ, Dron L, Harari O, Singer J, et al. Systematic review of basket trials, umbrella trials, and platform trials: a landscape analysis of master protocols. Trials 2019;20:572.

[63] Renfro LA, Sargent DJ. Statistical controversies in clinical research: basket trials, umbrella trials, and other master protocols: a review and examples. Ann Oncol 2017;28:34-43.

[64] Redman MW, Allegra CJ. The master protocol concept. Semin Oncol 2015;42:724-30.

[65] Atwood TF, Brown DW, Murphy JD, Moore KL, Mundt AJ, Pawlicki T. Care for patients, not for charts: a future for clinical medical physics. Int J Radiat Oncol Biol Phys 2018;100:21-2.

[66] Caudell JJ, Torres-Roca JF, Gillies RJ, Enderling H, Kim S, Rishi A, et al. The future of personalised radiotherapy for head and neck cancer. Lancet Oncol 2017; 18:e266-73.

[67] Sahiner B, Pezeshk A, Hadjiiski LM, Wang X, Drukker K, Cha KH, et al. Deep learning in medical imaging and radiation therapy. Med Phys 2019;46:e1-e36.

[68] Hounsell AR, Hawkins MA, Evans P. The challenge facing academic radiotherapy physics in the UK. Clin Oncol 2019;31:858-60.

[69] Michor F, Liphardt J, Ferrari M, Widom J. What does physics have to do with cancer?. Nat Rev Cancer 2011;11:657-70.

[70] White FM, Gatenby RA, Fischbach C. The physics of cancer. Cancer Res 2019;79:2107-10.

[71] Burmeister JW, Tracey MW, Kacin SE, Dominello MM, Joiner MC. Improving research in radiation oncology through interdisciplinary collaboration. Radiat Res 2018;190:1-4.

[72] European Commission. N 1681-6803 MJ-AX-14-002-EN-C Energy Protection Radiation $\mathrm{N}^{\circ} 174$ European Guidelines on Medical Physics Expert ISSN 16816803, 2014.

[73] World Health Organization. WHO report on cancer 2020. https://apps.who.int/ iris/bitstreams/retrieve.

[74] Atun R, Jaffray DA, Barton MB, Bray F, Baumann M, Vikram B, et al. Expanding global access to radiotherapy. Lancet Oncol 2015;16:1153-86.

[75] Lievens Y, Gospodarowicz M, Grover S, Jaffray D, Rodin D, Torode J, et al. Global impact of radiotherapy in oncology: saving one million lives by 2035 . Radiother Oncol 2017;125:175-7.

[76] Lievens Y, Ricardi U, Poortmans P, Verellen D, Gasparotto C, Verfaillie C, et al. Optimal health for all, together. ESTRO vision 2030. Radiother Oncol 2019;136:68-97. 